\title{
Chromosome numbers for the Italian flora: 8
}

\author{
Giovanni Astuti', Fabrizio Bartolucci², Liliana Bernardo ${ }^{3}$, \\ Fabio Conti ${ }^{2}$, Lorenzo Peruzzi ${ }^{1}$ \\ I Dipartimento di Biologia, Università di Pisa, Via Derna 1, 56126, Pisa, Italy 2 Centro Ricerche Floristiche \\ dell'Appennino (Università di Camerino - Parco Nazionale del Gran Sasso e Monti della Laga), San Colombo, \\ 67021, Barisciano (L'Aquila), Italy 3 Dipartimento di Biologia, Ecologia e Scienze della Terra (DiBEST), \\ Università della Calabria, 87030, Arcavacata di Rende (Cosenza), Italy \\ Corresponding author: Giovanni Astuti (gastuti@biologia.unipi.it)
}

Academic editor: G. Domina | Received 7 December 2019 | Accepted 9 December 2019 | Published 17 December 2019

Citation: Astuti G, Bartolucci F, Bernardo L, Conti F, Peruzzi L (2019) Chromosome numbers for the Italian flora: 8. Italian Botanist 8: 117-121. https://doi.org/10.3897/italianbotanist.8.49156

\begin{abstract}
In this contribution, new chromosome data obtained on material collected in Italy are presented. It includes three chromosome counts from two taxa endemic to Southern Italy (Centaurea subtilis and Onobrychis alba subsp. echinata) and one species (Poa ligulata) occurring in Italy with only one recently discovered population.
\end{abstract}

\section{Keywords}

Abruzzo, Basilicata, cytogeography, cytotaxonomy, Puglia, Southern Italy

\section{How to contribute}

Texts concerning new chromosome data should be submitted electronically to Giovanni Astuti (gastuti@biologia.unipi.it), including indications on voucher specimens and methods used. 


\section{Chromosome counts}

\section{Asteraceae}

\section{Centaurea subtilis Bertol.}

Chromosome number. $2 n=22$ (Fig. 1)

Voucher specimen. Italy. Basilicata. Belvedere di Murgia, Altopiano della Murgia Materana (Matera) (WGS84: 40.664530N, 16.616152E), ca. $400 \mathrm{~m}$ s.l.m., 25 August 2017, L. Peruzzi (PI n 014382).

Method. Squash preparations were made on root-tips obtained from germinating cypselae. Root tips were pre-treated with $0.4 \%$ colchicine for 3 hours and then fixed in Carnoy fixative solution for 1 hour. After hydrolysis in $\mathrm{HCl} 1 \mathrm{~N}$ at $60{ }^{\circ} \mathrm{C}$, the tips were stained in leuco-basic fuchsine.

Observations. Centaurea subtilis is endemic to Southern Italy, where it has been recorded for only two regions: Puglia and Basilicata. This is the first count for plants from Basilicata; the chromosome number found, $2 n=22$, is in accordance with the counts previously published for other populations from Puglia (Damboldt and Matthäs 1975, Bianco et al. 1991).

\section{G. Astuti, L. Peruzzi}

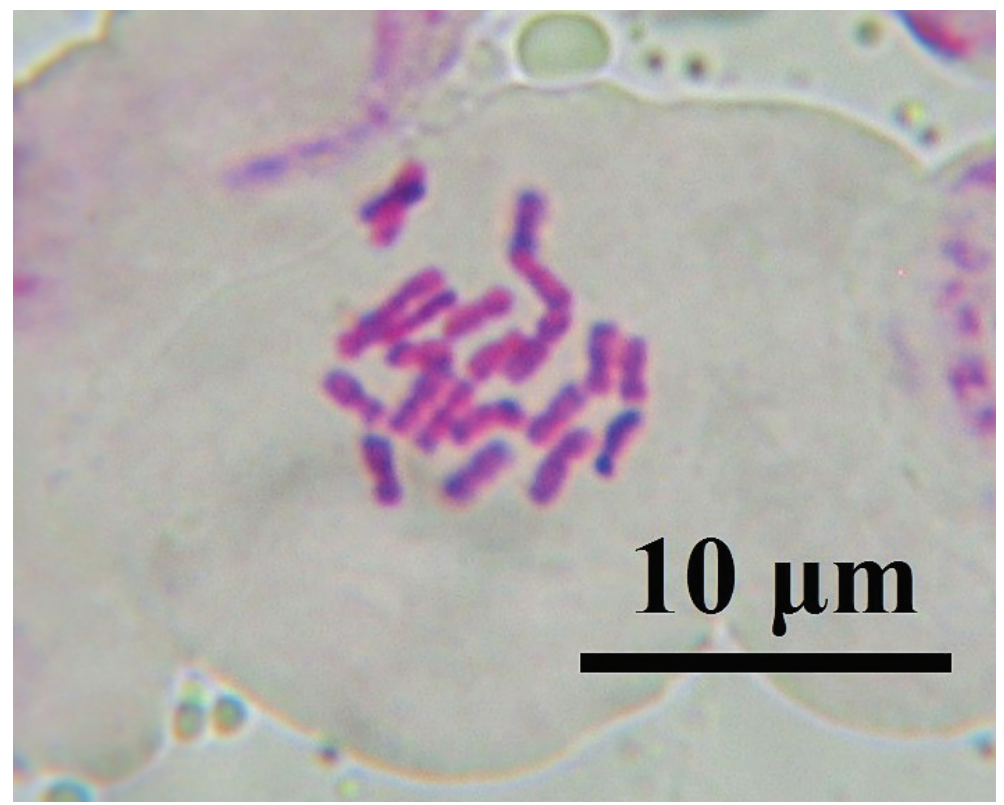

Figure I. Centaurea subtilis Bertol., $2 n=22$. Scale bar: $10 \mu \mathrm{m}$. 


\section{Fabaceae}

\section{Onobrychis alba (Waldst. \& Kit.) Desv. subsp. echinata (Guss.) P.W.Ball}

Chromosome number. $2 n=14$ (Fig. 2)

Voucher specimen. Italy. Puglia. Gravina di Leucaspide (Statte, Taranto) (WGS84: 40.566319N, 17.190559E), gariga, 150 m s.l.m., 25 June 2019, L. Bernardo \& G. Maiorca (CLU).

Method. Squash preparations were made on root-tips obtained from germinating seeds. Root tips were pre-treated with $0.4 \%$ colchicine for 3 hours and then fixed in Carnoy fixative solution for 1 hour. After hydrolysis in $\mathrm{HCl} 1 \mathrm{~N}$ at $60{ }^{\circ} \mathrm{C}$, the tips were stained in leuco-basic fuchsine.

Observations. Onobrychis alba subsp. echinata is endemic to Southern Italy, where it occurs in Puglia, Basilicata, and Calabria. Cenci et al. (2000) reported a chromosome number $2 n=2 x=14$ for all the Italian subspecies of $O$. alba, but without providing any information about the source of these data. Therefore, we report here the

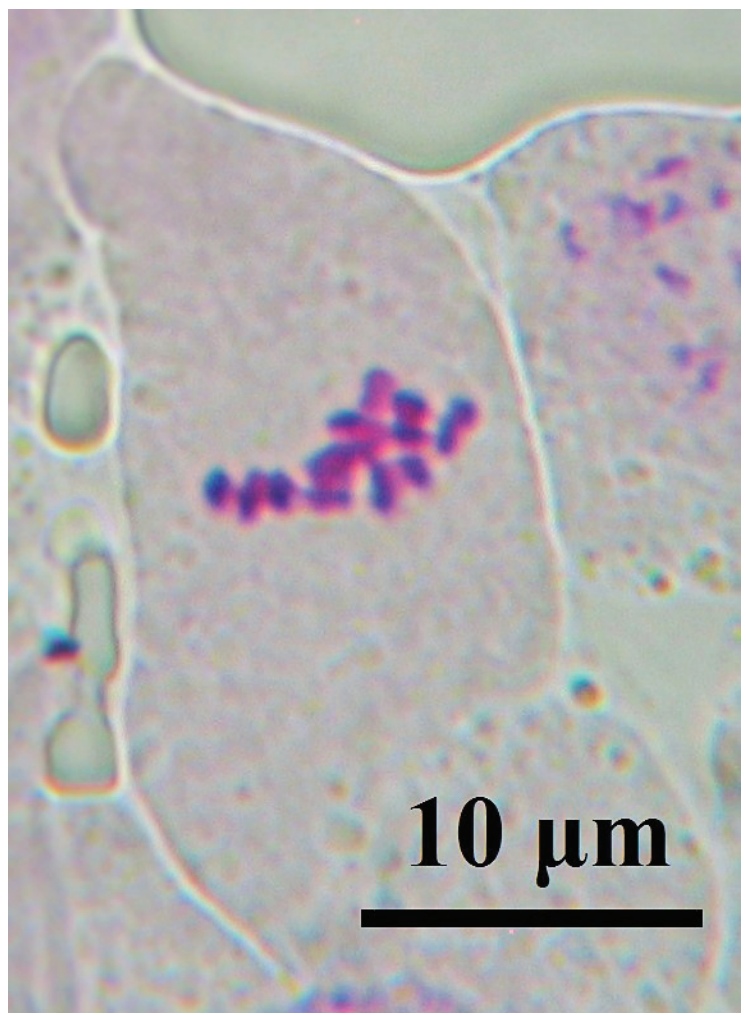

Figure 2. Onobrychis alba (Waldst. \& Kit.) Desv. subsp. echinata (Guss.) P.W.Ball, $2 n=14$. Scale bar: $10 \mu \mathrm{m}$. 
first count safely attributable to a well-defined population of $O$. alba subsp. echinata. This count is, however, in accordance with Cenci et al. (2000). Pedrotti and Cortini Pedrotti (1971) reported the same chromosome number for a population of O. alba subsp. alba from Umbria. Our count supports the differentiation of this taxon from $O$. calabrica Širj., a tetraploid species with $2 n=4 x=28$ chromosomes, endemic to a small area in south-eastern Calabria (Bernardo et al. 2018).

G. Astuti, L. Bernardo

\section{Poaceae}

\section{Poa ligulata Boiss.}

Chromosome number. $2 n=14$ (Fig. 3)

Voucher specimen. Italy. Abruzzo. Salendo a Cima delle Murelle in loc. La Carozza (Pennapiedimonte, Chieti) (WGS84: 42.11324N, 14.14273E), rupi e pendii rupestri, 2300 m, 2 August 2011, F. Bartolucci \& F. Conti (APP n59214).

Method. Squash preparations were made on root tips obtained from cultivated plants. Root tips were pre-treated with $0.4 \%$ colchicine for $4 \mathrm{~h}$ and then fixed in Carnoy solution for $1 \mathrm{~h}$. After hydrolysis in $1 \mathrm{~N} \mathrm{HCl}$ at $60^{\circ} \mathrm{C}$, the tips were stained with leuco-basic fuchsine.

Observations. Poa ligulata occurs in the Iberian Peninsula and NW Africa (Ortega-Olivencia and Devesa 2018). It was not recorded for the Italian flora until recently (Bartolucci et al. 2018, Conti et al. 2019). This is the first chromosome count for this species in Italy (Bedini et al. 2010 onwards), and it agrees with previous chromosome

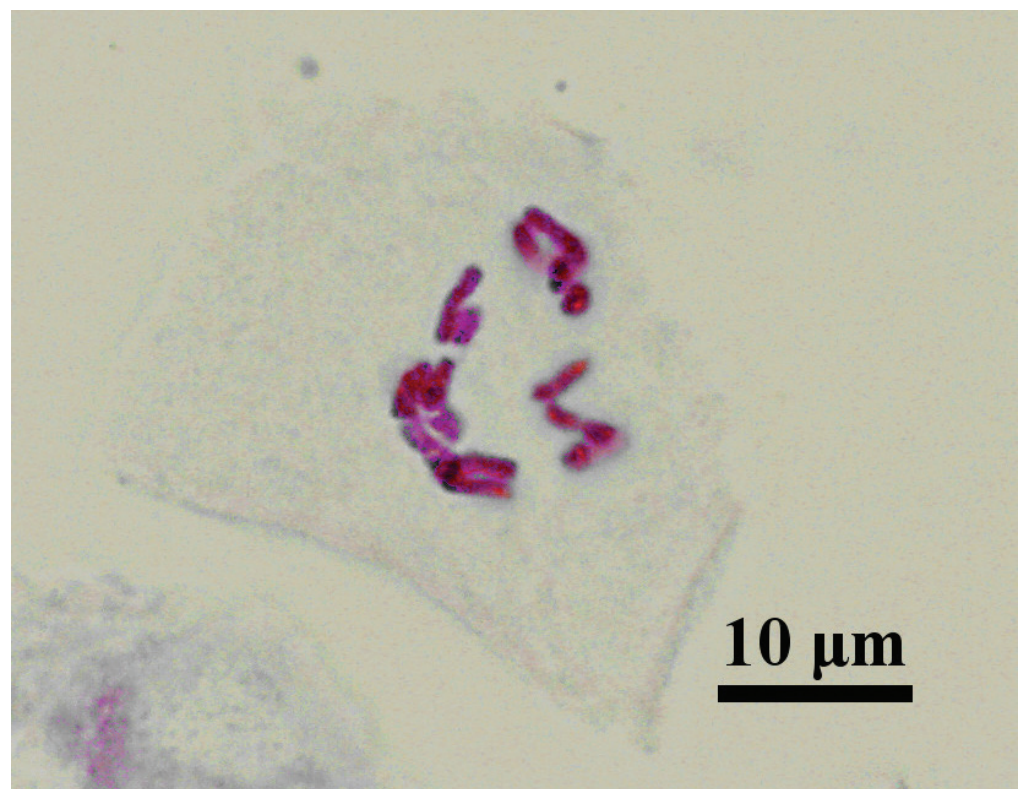

Figure 3. Poa ligulata Boiss., $2 n=14$. Scale bar: $10 \mu \mathrm{m}$. 
numbers published from Spain (Küpfer 1968, Löve and Kjellqvist 1973). On the basis of a preliminary morphological analysis, the population from central Italy shows peculiar features, and a taxonomic study is in progress.

F. Bartolucci \& F. Conti

\section{Acknowledgements}

GA and LP are grateful to Antonio Giacò and Lorenzo Pinzani for their help in laboratory activities.

\section{References}

Bartolucci F, Peruzzi L, Galasso G, Albano A, Alessandrini A, Ardenghi NMG, Astuti G, Bacchetta G, Ballelli S, Banfi E, Barberis G, Bernardo L, Bouvet D, Bovio M, Cecchi L, Di Pietro R, Domina G, Fascetti S, Fenu G, Festi F, Foggi B, Gallo L, Gottschlich G, Gubellini L, Iamonico D, Iberite M, Jiménez-Mejías P, Lattanzi E, Marchetti D, Martinetto E, Masin RR, Medagli P, Passalacqua NG, Peccenini S, Pennesi R, Pierini B, Poldini L, Prosser F, Raimondo FM, Roma-Marzio F, Rosati L, Santangelo A, Scoppola A, Scortegagna S, Selvaggi A, Selvi F, Soldano A, Stinca A, Wagensommer RP, Wilhalm T, Conti F (2018) An updated checklist of the vascular flora native to Italy. Plant Biosystems 152(2): 179-303. https://doi.org/10.1080/11263504.2017.1419996

Bedini G, Garbari F, Peruzzi L (2010 onwards) Chrobase.it. Chromosome numbers for the Italian flora. http://bot.biologia.unipi.it/chrobase/ [accessed 29 October 2019]

Bernardo L, Maiorca G, Franzoni J, Roma-Marzio F, Peruzzi L (2018) Dati preliminari su Onobrychis calabrica (Fabaceae) specie endemica italiana misconosciuta. Notiziario della Società Botanica Italiana 2(2): 71-72.

Cenci CA, Bassi G, Ferranti F, Romano B (2000) Some morphometric, anatomical and biochemical characteristics of fruits and seeds of Onobrychis spp. in Italy. Plant Biosystems 134(1): 91-98. https://doi.org/10.1080/11263500012331350395

Conti F, Ciaschetti G, Di Martino L, Bartolucci F (2019) An annotated checklist of the vascular flora of Majella National Park (Central Italy). Phytotaxa 412(1): 1-90. https://doi. org/10.11646/phytotaxa.412.1.1

Damboldt J, Matthäs U (1975) Chromosomenzahlen einiger mediterraner und mitteleuropäischer Centaurea-Arten (Asteraceae). Plant Systematics and Evolution 123: 107-115. https://doi.org/10.1007/BF00981769

Küpfer P (1968) Nouvelles prospections caryologiques dans le flore orophile des Pyrenees et de la Sierra Nevada. Bulletin de la Société Neuchâteloise des Sciences Naturelles 91: 87-104.

Löve A, Kjellqvist E (1973) Cytotaxonomy of Spanish plants. II. Monocotyledons. Lagascalia 3(2): 147-182.

Ortega-Olivencia A, Devesa JA (2018) Updated checklist of Poa in the Iberian Peninsula and Balearic Islands. PhytoKeys 103: 27-60. https://doi.org/10.3897/phytokeys.103.26029

Pedrotti F, Cortini Pedrotti C (1971) Numeri Cromosomici per la Flora Italiana: 13-18. Informatore Botanico Italiano 3(1): 47-51. 